\title{
OS MEIOS ALTERNATIVOS DE GESTÃO DE CONFLITOS COMO CONCRETIZAÇÃO DA AUTONOMIA PRIVADA NO DIREITO DE FAMÍLIA
}

\author{
Gabriela Martins Carmo ${ }^{1}$ \\ Carlos Marden ${ }^{2}$
}

\section{RESUMO}

O trabalho visa analisar a necessidade de processo judicial para gestão de interesses no âmbito do direito de família. Para tanto é examinada: a autonomia privada neste ramo, a função do processo judicial em um Estado Democrático de Direito e a possibilidade do uso de meios alternativos de resolução na gestão de conflitos. Como metodologia, a pesquisa foi realizada de forma bibliográfica e qualitativa. Conclui-se que o processo judicial serve para garantir direitos fundamentais, devendo ser utilizado em situações que envolvam incapazes. Nos demais casos, porém, meios alternativos de gestão de conflitos se mostram capazes de privilegiar a autonomia privada.

Palavras-chaves: autonomia privada; família; direito ao processo; mediação; gestão de conflitos.

\section{ALTERNATIVE MEANS OF CONFLICT MANAGEMENT AS CONCRETIZATION OF PRIVATE AUTONOMY IN FAMILY LAW}

\begin{abstract}
The paper aims to analyze the need for a judicial process for conflict management in the context of family law. To this end it examines: private autonomy within this branch, the role of judicial process in a democratic state of law, and the possibility of using alternative means of conflict resolution. As a methodology, the research was carried out in bibliographical and qualitative way. It is concluded that the judicial process serves to guarantee fundamental rights, and should be used in situations involving incapacitated. In other cases, however, alternative means of conflict management are able to privilege private autonomy.
\end{abstract}

Keywords: private autonomy; family; process as right; mediation; conflict management.

\section{INTRODUÇÃO}

O Estado tem por função cuidar e proteger a família, já que esta é um importante núcleo social que afeta diretamente todos os outros. Com as mudanças sociais e o surgimento de um novo conceito de família, novos arranjos familiares e, consequentemente, novos conflitos de família aparecem. A individualidade, a afetividade e a autonomia privada foram

\footnotetext{
${ }^{1}$ Mestranda em Direito e Desenvolvimento pela Unichristus, Brasil. E-mail: gabrielamartinscarmo@gmail.com.

${ }^{2}$ Pós-Doutorando em Ciências Sociais Aplicadas pela Universidade do Vale do Rio dos Sinos, UNISINOS, Brasil.

E-mail: carlosmardencc@hotmail.com
} 
exaltadas de forma a colocar em discussão até que ponto cabe ao Estado intervir diretamente no núcleo familiar.

Diante do panorama acima apresentado, surgem as seguintes dúvidas: se o Estado já não deve intervir tanto na vida privada e se paralelamente surgem novos tipos de conflitos familiares, qual o mecanismo adequado para resolvê-los? Será que o processo judicial é esse meio? A função de um processo é solucionar problemas? Por esses questionamentos, o objeto desta pesquisa é saber como lidar com esses conflitos familiares que surgem na "era da autonomia privada".

Esta discussão se mostra essencial para que haja uma desmistificação da função do processo judicial e para analisarmos as possibilidades de mecanismos de resolução de conflitos no âmbito familiar. Acredita-se que o processo tenha por função garantir direitos fundamentais das partes, tendo que ser assegurado obrigatoriamente nos casos em que alguma parte possui alguma incapacidade de exprimir sua vontade, podendo a mediação ser utilizada nos demais casos, por privilegiar a autonomia da vontade dos envolvidos.

Para alcançar tal finalidade da pesquisa, o presente trabalho fora subdivido em três partes. O primeiro tópico aborda a questão da autonomia privada no âmbito do Direito de Família, fazendo uma análise histórica e social do conceito de família e seus efeitos. O segundo tópico, aborda a tese do processo como metodologia de garantia dos direitos fundamentais, fazendo o histórico comparativo entre a escola processual instrumentalista e a teoria constitucional democrática. Por fim, no terceiro tópico se busca responder ao problema inicial da pesquisa, utilizando os conceitos e análises de pontos-chaves feitos nos dois tópicos anteriores para averiguar até que ponto há a necessidade de um processo judicial para garantir direitos fundamentais das partes em detrimento da autonomia privada e vice-versa.

Do estudo se conclui que, com exceção dos casos que envolvem menores ou incapazes (nos quais realmente é essencial a intervenção do Estado através do processo judicial), nos demais casos de direito de família, deve-se privilegiar a autonomia da vontade das partes através do instituto da mediação, pois, como a família é um núcleo de pessoas que se reúnem pelo afeto, nada melhor do que lhes seja dada a possibilidade de (através de um diálogo guiado) chegar a um acordo sobre seus dilemas.

\section{AUTONOMIA PRIVADA NO ÂMBITO DO DIREITO DE FAMÍLIA}


A família é a base da sociedade. Ela é o primeiro meio de interação do ser humano com o mundo. Nela se aprende o valor social da cultura inserida, tem-se suas primeiras referências e se forma a personalidade do indivíduo. É no bojo familiar que as pessoas passam pelas principais experiências de transformação em um ser social, pois "o homem é o resultado do meio cultural em que foi socializado".

"Ele é herdeiro de um longo processo acumulativo, que reflete o conhecimento e a experiência adquirida pelas numerosas gerações que o antecederam" (LARAIA, 1986, p. 45). Inclusive, seria um grave erro acreditar que por ela não possuir um mecanismo formal de coerção, não seria ela o principal instrumento de controle e manutenção do funcionamento da sociedade, pois é nela que se encontram os laços sociais mais importantes de um ser humano (BERGER , 1986) .

Diante da tamanha importância do menor núcleo social, o Direito de família vem como uma maneira do Estado regulamentar os atos desta, já que, como base da sociedade, é capaz de provocar mudanças significativas em toda a estrutura vigente. Assim, a simples modificação do conceito de família reverbera em drásticas mudanças sociais.

Nos primórdios da humanidade, acredita-se que a sociedade era matriarcal: o centro da família era a figura feminina, que tinha vários homens como companheiros e cuidava dos filhos enquanto aqueles caçavam. Por motivos que ainda não foram confirmados pela sociologia, esse cenário foi se modificando, dando espaço para o surgimento do modelo patriarcal. $O$ centro familiar, então, passou a ser a figura paterna.

Instituiu-se o casamento e a ideia de uma família principal, e a ocorrência de relacionamentos paralelos heterossexuais ou homoafetivos eram comuns. Assim permaneceu por quase toda a antiguidade até a chegada do Cristianismo. A monogamia então foi oficializada e qualquer conduta extramatrimonial se tornou socialmente reprovável, em especial, relacionamentos homoafetivos. Este modelo familiar só se fortaleceu ao longo dos dezoito séculos seguintes.

O modelo patriarcal era fruto e consequência do conceito de família, sendo a união de um homem e uma mulher com objetivo de procriação e estabilidade financeira. O homem sustentava a casa, a mulher era vista como uma propriedade do marido e cuidava do lar e dos filhos, e estes deviam uma obediência extrema àqueles.

Esse panorama vivido por séculos e séculos foi modificado com a entrada da mulher no mercado de trabalho, pois, com o advento da revolução industrial, o uso de uma mão de 
obra mais barata e igualmente qualificada à do homem se fez útil. Assim a mulher passou a trabalhar. Ademais, com o capitalismo se fortalecendo pelo mundo, uma renda maior em casa era algo interessante, já que então as famílias poderiam consumir mais produtos feitos pelas empresas.

Não podia ainda se falar em igualdade entre sexos, até porque as mulheres ganhavam bem menos que os homens e não podiam ocupar cargos de chefia. Mas, assim como a abolição da escravatura foi o começo de um processo lento de humanização para pessoas afrodescendentes, a entrada da mulher no mercado de trabalho foi o início de uma conscientização da importância da mulher na sociedade.

As mulheres começaram a auferir renda e a passar mais tempo longe de casa. Os filhos passaram a ser criados por babás ou irem à escola em idade mais tenra. O "empoderamento" dos demais membros promoveu uma maior igualdade de forças entre estes. Como resultado, tem-se famílias cada vez menores e unidas não mais só por um aspecto financeiro.

Resumindo, com a saída da mulher do lar para o mercado de trabalho, a organização dentro da casa teve de ser modificada e a formação da família também. Diante dessa maior igualdade de forças, deixa, aos poucos, de fazer sentido o conceito tradicional patriarcal de família. Mais do que isso, impende apontar que o progressivo empoderamento da mulher tem reflexos na tradicional percepção de sua hipossuficiência.

Vale salientar que com a ocorrência das $1^{\mathrm{a}}$ e $2^{\mathrm{a}}$ guerras mundiais, essa necessidade de a mulher trabalhar aumentou até ao ponto de não só se tornar comum, mas necessária essa quebra de paradigma social em que o homem era quem sustentava a casa. Movimentos como o feminismo ficaram mais fortes. A ONU também fez campanhas de conscientização da necessidade de igualdade entre homens e mulheres e de proteção à criança e ao adolescente. Ou seja, na segunda metade do século XX, em um cenário de democratização e humanização de um mundo que ainda sofria as influências dos pós-guerras, a globalização e a recriação das Constituições veio acelerar essas mudanças na autonomia privada, como explica Couto (2009, online):

Foram constituições que passaram a prever direitos positivos, atuações no Estado. Essas constituições modernas (apoiadas também em convenções da ONU sobre direitos humanos) passaram a indicar o respeito à dignidade da pessoa humana como princípio fundamental dos respectivos Estados, como, por exemplo, a Constituição brasileira, que mais interessa aqui. Aparecem, então, os princípios como da boa-fé, da função social, da onerosidade excessiva, do abuso de direitos como mecanismos 
de regulação estatal na esfera privada, todos reduzindo a esfera de auto-regulação (autonomia privada)

No Brasil, só em meados dos anos 80 é que esse processo se intensifica. Com a industrialização do país e o fim da ditadura militar, a luta por liberdade social e individual cresce. Não só liberdade econômica, mas também liberdade individual, ou melhor, autonomia individual, em especial dentro do núcleo familiar. Este processo fica claro com a promulgação da Constituição de 1988 e seu artigo 226:

Art. 226. A família, base da sociedade, tem especial proteção do Estado.

$\S 1^{\circ} \mathrm{O}$ casamento é civil e gratuita a celebração.

$\S 2^{\circ} \mathrm{O}$ casamento religioso tem efeito civil, nos termos da lei.

$\S 3^{\circ}$ Para efeito da proteção do Estado, é reconhecida a união estável entre o homem

e a mulher como entidade familiar, devendo a lei facilitar sua conversão em casamento.

$\S 4^{\circ}$ Entende-se, também, como entidade familiar a comunidade formada por qualquer dos pais e seus descendentes.

$\S 5^{\circ}$ Os direitos e deveres referentes à sociedade conjugal são exercidos igualmente pelo homem e pela mulher.

$\S 6^{\circ} \mathrm{O}$ casamento civil pode ser dissolvido pelo divórcio. (Redação dada Pela Emenda Constitucional no 66, de 2010)

$\S 7^{\circ}$ Fundado nos princípios da dignidade da pessoa humana e da paternidade responsável, o planejamento familiar é livre decisão do casal, competindo ao Estado propiciar recursos educacionais e científicos para o exercício desse direito, vedada qualquer forma coercitiva por parte de instituições oficiais ou privadas.

$\S 8^{\circ} \mathrm{O}$ Estado assegurará a assistência à família na pessoa de cada um dos que a integram, criando mecanismos para coibir a violência no âmbito de suas relações. (grifo nosso)

Ao ler o texto supracitado, percebe-se nitidamente a democratização da família e um maior afastamento do Estado deste núcleo. A família deixa de ser protegida pelo aspecto patrimonial para ser protegida pela sua importância social. Sobre este novo panorama, Tepedino (2006, p.02) explica que:

Verifica-se, do exame dos arts. 226 a 230 da Constituição Federal, que o centro da tutela constitucional se desloca do casamento para as relações familiares dele (mas não unicamente dele) decorrentes; e que a milenar proteção da família como instituição, unidade de produção e reprodução dos valores culturais, éticos, religiosos e econômicos, dá lugar à tutela essencialmente funcionalizada à dignidade de seus membros, em particular no que concerne ao desenvolvimento da personalidade dos filhos.

Não cabe mais ao Estado intervir diretamente e constantemente nesta, como antes fazia, pois o conceito e a função dela mudaram, já que com a Constituição o Brasil assumiu 
sua identidade de Estado Democrático de Direito, em que os princípios se tonaram ainda mais fortes e numerosos, como aduz Battochio (2014, p.02):

\begin{abstract}
A utilização da expressão 'Estado Democrático de Direito' pelo artigo $1^{\circ}$ da Constituição Federal de 1988 traz repercussões em toda interpretação jurídica, buscando superar o simples Estado de Direito concebido pela corrente do Liberalismo. O 'Estado Democrático de Direito' busca garantir não apenas a proteção dos direitos, ele pretende ir além. Ele visa defender o estabelecimento de um rol de garantias fundamentais, baseadas no princípio da dignidade da pessoa humana.
\end{abstract}

Assim, resumidamente, com esta nova carga axiológica da Constituição e especialmente após a promulgação do Código Civil de 2002, o Estado abandonou o modelo da família patriarcal que concebia desde a época do Império e introduziu novos valores à sociedade ( LÔBO, 2011, p. 17). Socialmente se oficializou a consciência de que existem sentimentos nos familiares, passando a se considerar o afeto nessas relações. O conceito de família então se transformou em: pessoas que se unem através de laços afetivos.

Vale salientar que, obviamente, se o conceito e a função da família se modificam, os formatos desta também irão sofrer mudanças. Novos arranjos surgem, como, por exemplo: casais que se unem em união estável; que decidem não ter filhos; casamentos que terminam; o surgimento de famílias monoparentais; jovens que saem da casa dos pais e vão morar sozinhos por toda a vida; família adotivas; famílias mosaico; netos que são educados pelos avós, dentre outros exemplos.

Notoriamente, esse processo não foi totalmente linear e óbvio como abordado no presente trabalho. Como toda grande mudança social da história, nos períodos de revoluções sociais ocorrem avanços e logo depois pequenos retrocessos seguidos por novos avanços. Nas transformações familiares foi da mesma forma. Chegou-se a falar (fala-se até hoje) em crise da família brasileira, como expõe Souza (2008, online):

Ao longo das últimas décadas o debate sobre a crise da família, no Ocidente, foi propiciado pelos efeitos da generalizada aceitação social do divórcio, do declínio da instituição do casamento e da baixa taxa de fecundidade. Esses acontecimentos tanto indicaram a compreensão de que se delineara o enfraquecimento da família, quanto sugeriram a análise do surgimento de novos modelos familiares, caracterizados, por sua vez, pelas mudanças nas relações entre os sexos e as gerações, tais como: controle mais intenso da natalidade, autonomia relativa da sexualidade referente à esfera conjugal (posto que o exercício da atividade sexual deixa de estar circunscrito à esfera do matrimônio), inserção massiva da mulher no mercado de trabalho, questionamento da autoridade paternal, atenção ao desenvolvimento das necessidades infantis e dos idosos, entre outras. 
$\mathrm{Na}$ verdade, a família moderna (ou pós-moderna, como alguns chamam) ainda está em desenvolvimento. Muitos temas ainda são completos tabus sociais, como adoção homoafetiva, poliamorismo, relacionamentos abertos, dentre outros novos modelos familiares. A intenção deste trabalho não é adentrar no mérito da legitimidade ou não destes novos conceitos, e, sim, apenas afirmar que na prática eles existem, tendo ou não uma grande aceitação social. É abordar a liberdade individual de cada ser em face do princípio da afetividade contido no conceito de família.

A questão que surge nesse panorama é: qual o grande efeito dessa mudança de conceito? A resposta mais plausível é: uma maior autonomia entre todos os entes familiares. Já que cada pessoa passa a ter poderes individuais e a desenvolver sua identidade, as particularidades inatas a cada ser humano aumentam. Cada núcleo familiar terá mais especificidades e serão mais independentes entre si e menos tolhidos pela sociedade por serem diferentes. A afetividade, o cuidado e o carinho estão correlacionados com a autonomia familiar.

Uma consequência prática disto é que novos tipos de conflitos irão surgir e isso, somado ao fato de que o Estado cada vez menos poderá intervir na vida privada, cria um sério problema. E é justamente isso que será abordado no último tópico: até que ponto as famílias deverão solucionar seus conflitos precisando do Estado? Qual a função de um processo judicial? Um processo é o meio adequado para solucionar conflitos familiares? Existem outras alternativas? Para solucionar tais dúvidas, primeiramente temos que entender o significado e a função do processo judicial em sua integralidade, que é o que será abordado no tópico a seguir.

\section{PROCESSO COMO METODOLOGIA DE GARANTIA DOS DIREITOS FUNDAMENTAIS}

Até o século XIX, não havia nenhuma divisão concreta entre Direto Processual e Direito Material, consequentemente, não havia uma unificação de normas processuais em um país. Os julgamentos eram realizados por juízes que não possuíam uma comarca específica, iam de carroça por todo o território e, em cada vilarejo que paravam, recebiam as demandas da população, julgando conforme seu entendimento, sem ter um rito ou procedimento unificado. 
Nesse modelo de Poder Judiciário, os processos chegavam a demorar um século para serem resolvidos e não davam tanta segurança jurídica às partes como hoje, já que cada juiz realizava um procedimento processual diferente. Por outro lado, esse arcaico processo judicial, para a época, representava um grande avanço social, pois antes dele, as pessoas solucionavam seus problemas por meio da autotutela ou de autoridades não devidamente constituídas.

Na Alemanha, em 1868, Oscar Bülow propôs a separação entre direito processual e direito material e, por isso, Zamora e Castillo ( 1947, p.293) explicam que "el derecho procesal como ciência arranca de Oscar Bülow”. Ele percebeu que havia uma diferenciação no tipo de relação que as pessoas possuíam na lide das relações que as pessoas possuíam em um processo. Nas palavras do próprio Bülow (1964, p. 1):

\footnotetext{
Nunca se ha dudado que el derecho procesal civil determina las faculdades y los deberes que ponen en mutua vinculación a las partes y al tribunal. Pero, de esa manera, se ha afirmado también, que el proceso es una relación de derechos y obligaciones recíprocos, es decir, una relación jurídica. [...] Se acostumbra a hablar tan solo de relaciones de derecho privado. A estás, sin embargo, no puede ser referido el proceso.
}

O autor distingue o direito processual do direito material afirmando que, no processo se possui uma relação jurídica contínua que se desenvolve por etapas. As partes do processo permanecem vinculadas durante ele todo, que possui vários momentos diferentes. Ademais, o Estado, na figura do Juiz, também está envolvido no processo. Por outro lado, no direito material a relação jurídica é pontual, dá-se no momento do ato jurídico e ocorre entre particulares.

Franz Klein, jurista Austríaco, com base nas ideias de Oscar Bülow, criou o famoso Código de Processo Civil austríaco. Como explicam Zamora e Castillo ( 1947, p.311), ao falar do projeto de Klein “ su larga permanência en el ministério de Justicia le permitió, a todo lo largo del decênio 1890-1900, planear, redactar e implantar la reforma del processo civil, que ha imortalizado su nombre[...] y hacer mas eficaz y expeditiva la justicia civil de sus países". Sem dúvidas, esse feito de Franz Klein, criou uma segurança jurídica e uma uniformização de normas que permitiram tornar mais eficaz a justiça da época.

$\mathrm{Na}$ Itália, Chiovenda deu o rigor cientifico às normas processualistas, tendo seu pensamento influenciado o Código de Processo Civil Italiano de 1940. Seu conceito de processo era uma relação jurídica entre as partes, pois seria este "um enlace normativo entre 
duas pessoas as quais uma pode exigir da outra o cumprimento de um dever jurídico" (GONÇALVES, 2012, p.62). Criticado por muitos como alguém que teria copiado o modelo germânico iniciado por Oscar Bülow e aplicado na Itália, em verdade, Giuseppe Chiovenda foi importante para o direito Italiano, como Bülow foi para o alemão (ZAMORA E CASTILLO, 1947, p. 313).

O jurista italiano que deu continuidade e contribuiu para a divulgação do pensamento de Giuseppe Chiovenda foi Francesco Carnelutti. Carnelutti "trabalha com a noção de solução de conflito como ponto convergente da Jurisdição" (BARROS, 2003, p. 17). Ou seja, com ele se desenvolve a ideia de que a função do processo seria solucionar conflitos, dentre outras contribuições, como expõem Zamora e Castillo (1947, p. 316):

Tres postreras indicaciones acerca de Carnelutti: $1^{\text {a }}$, desde 1924, en que se funda, Carnelutti ha sido algo más que el director: el alma y el motor de la "Rivista di Diritto Processuale Civille"[...], la mejor de su especialidad, desde luego, y quizás, también la mejor revista jurídica del mundo; $2^{\mathrm{a}}$, la piedra angular de su pensamiento procesal civil la constituye la nocíon de Litis o litígio , concebido por el cómo idea extra o meta procesal, a cuya justa composicíon está adstricto el proceso, y, $3^{\mathrm{a}}$, como Goldschmidt en Alemania, Carnelutti es uno de los poquíssimos procesalistas que ha cultivado, aunque con desigual intensidad, tanto el enjuiciamiento civil como el penal.

Pouco antes do período da $2^{\mathrm{a}}$ guerra mundial, Enrico Tullio Liebman, jurista e professor processualista na Itália, veio morar no Brasil, trazendo consigo o formato processual do Direito Italiano. Para ele, o processo busca o ato final, o provimento do juiz, e o procedimento processual, que seria uma série de atos que se sucedem no processo e desenvolvem-se com a participação, não só do juiz, mas também das partes, autor e réu. Além disso, "Liebman reabilitou o conceito de procedimento, já que considera o processo uma entidade complexa, integrada pela relação jurídica e pelo procedimento." (BARROS, 2003, p. 11).

Foi a partir do seu conceito de jurisdição, acima apresentado, que seus principais discípulos brasileiros: Alfredo Buzaid e Cândido Rangel Dinamarco, solidificaram esses pensamentos no Brasil. O primeiro através da elaboração do Código de Processo Civil Brasileiro de 1973, o segundo através da ideia de que "a jurisdição é instrumento para a pacificação social, e o processo possui escopos metajurídicos, sociais, políticos e jurídicos" (BARROS, 2003, p. 17).

É uma ideia tentadora imaginar que o Estado possa efetivar suas políticas públicas e melhorar a vida de seus cidadãos através da figura do juiz em um processo judicial, como 
propõe Candido Rangel Dinarmarco, possuindo o processo para tanto, a função de educar a população através do resultado das sentenças. Esse entendimento de processo acima descrito é o que é adotado pela maioria dos juristas brasileiros.

Esse entendimento é batizado como a Escola Instrumentalista, pois afirma que o processo é um instrumento da jurisdição para realizar os escopos metajurídicos do Estado, como a resolução de conflitos em busca da paz social. É uma teoria deslumbrante, porém nela o Estado possui um caráter autoritário e intervencionista, através da figura do juiz. O juiz possuiria a função de promover a paz social, efetivando as metas (os escopos) governamentais e políticas do Estado. Porém, existe outro entendimento sobre processo.

Ainda no começo do século XX (1923), o alemão James Goldschmidt discordou da definição que existia à época sobre o processo ser uma relação jurídica entre as partes. Ele explicava que a ideia de relação jurídica é uma característica estática do direito privado, não aplicável ao direito processual, que possui característica dinâmica. Para James Goldschmidt, o que existe no processo é uma situação jurídica, na medida em que, a cada momento processual, cada sujeito está colocado em determinado posição jurídica em face da lei, não se podendo falar que desenvolva qualquer tipo de relação jurídica com os demais sujeitos (BARROS, 2003, p.14).

Por outro lado, em 1967, outro italiano (FAZZALARI, 2006, p.120) demonstrou que o foco das discussões do processo não deveriam ser que tipo de relação ou situação existiria entre as pessoas que participam do processo, e sim, o conceito do processo em si, diferindo este de procedimento, estruturando-o e caracterizando o processo como objeto do contraditório. Essa ideia fora batizada de Teoria Estruturalista.

Anos depois, já passadas a $2^{\mathrm{a}}$ guerra mundial e a "onda mundial" de governos ditatoriais, com a promulgação da constituição Italiana, o " Il modelo costitucionale del processo civile italiano" abordando a influência da Constituição no processo foi escrito por Andolina e Vignera, ( 1997 , p. 11) : "Tutto ciò permete di dire che dopo il 1948 il processo in Italia è diventato un' entità “ a modello unico ed a tipologia plurima” [...] I'idea che, se esiste un solo paradigma costituzionale de proceso".

O grande mérito deles foi perceber que a Constituição não apenas influenciava o processo, mas também, que dentro dela havia um modelo de processo a ser seguido. Assim, Andolina e Vignera ( 1997, p. 09) caracterizaram o processo constitucional: 
Prima di prendere in considerazione i singoli elementi ( oggettivi e soggettivi) del modelo costituzionale del processo civile, è doveroso evidenciare in questa sede $\mathrm{i}$ suoi caratteri generali, che possono individuarsi: a) nella espansività, consistente nella sua idoneità [...] a condizionare la fisionomia dei singoli procedimenti giurisdizionale introduttidal legislatore ordinario[...]; b-) nella variabilità, indicante la sua attitudine ad assumere forme diversa di guisa che I'adeguamento al modello costituzionale [..] delle figura processuali concretamente funzionanti puó avvenire secondo varie modalità in vista de perseguimiento di particolari scopi; c-) nella perfettibilità, designante la sua idoneità ad essere perfeizonato dalla legislazione sub-costituzionale, la quale [...] ben puó costruire procedimenti giurisdizionale carratterizzati da (ulterior) garantiza ed istituti ignotà al modello costituzionale[...].

Essa visão constitucionalista se desenvolveu e foi trazida ao Brasil por volta dos anos 80, época em que o Brasil criou sua primeira constituição democrática. O responsável por trazer e aperfeiçoar essa teoria no país foi José Alfredo de Oliveira Baracho, como aduz Santos (2015, online):

[...]Dr. Baracho, apresentou a Teoria Constitucionalista do Processo no Brasil. Para esse autor o Processo Constitucional tem como finalidade a efetivação das garantias constitucionais, como são vistas atualmente, isto é, como instrumentos predominantemente processuais, relacionados a reintegração da ordem constitucional. Essas garantias de que fala Baracho, são sobretudo aquelas que dizem respeito ao acesso ao judiciário, ao devido processo legal, à ampla defesa e ao contraditório, que se encontram dispostas no art. $5^{\circ}$ da Constituição Federal vigente. A garantia de processo que se apresenta na Constituição da República pode ser caracterizada como um verdadeiro princípio, que tem amparo constitucional e processual. (grifo nosso)

Essa teoria apresentada por José Alfredo de Oliveira Baracho, em resumo, explica que a função do processo é garantir direitos fundamentais às partes, como o contraditório, por exemplo. Ela não entende que o processo tenha por função solucionar conflitos. Obviamente, esses são solucionados como uma consequência indireta do processo, mas isso não é a sua função. Tampouco, seria função do Estado realizar no processo qualquer tipo de escopo social ou político. A figura estatal serviria apenas para garantir o respeito aos direitos fundamentais constitucionalmente previstos.

Dessa forma, percebe-se que essa teoria possui um caráter essencialmente democrático, ao contrário da teoria instrumentalista do processo que possui em sua essência a figura de um Estado autoritário. Assim, apesar de a escola instrumentalista ter sido mais difundida pelo país, como se observa que a teoria democrática é mais adequada a um país como o Brasil que é definido como democrático, será essa a utilizada no decorrer deste estudo. 


\section{DIREITO DE FAMÍliA: ENTRE A AUTONOMIA PRIVADA E A GARANTIA} JUDICIAL

Explicadas as ideias de autonomia na família e da visão democrática do processo nos tópicos anteriores, essenciais para essa parte do trabalho, se prossegue para responder aos seguintes questionamentos inicias da pesquisa: Qual a função de um processo judicial na família? Um processo é o meio adequado para solucionar conflitos familiares? Até que ponto as famílias deverão solucionar seus conflitos precisando de um processo? Existem outras alternativas?

A resposta ao primeiro questionamento é, sem dúvidas, garantir direitos fundamentais dos membros familiares. Como se demonstrou, o processo é uma tecnologia criada para evitar a autotutela. Foi uma alternativa dada pelo Estado para proteger e resguardar os direitos das pessoas e garantir que todos tivessem acesso ao contraditório e que ninguém fosse apenado sem a mínima razoabilidade. A função do juiz como terceiro imparcial tem essa serventia.

Um processo não tem por função solucionar conflitos. Ele não existe para resolver um problema, se fosse assim, qualquer conflito sempre recairia no Poder Judiciário. Um processo também não tem por função dar uma resposta rápida a sociedade. Tampouco tem por função ser uma forma de imposição da vontade do estado sobre a vida privada. Ele é simplesmente um meio de garantir direitos fundamentais das pessoas.

É necessário desmistificar todos esses aspectos para que se compreenda realmente que o processo é apenas uma alternativa para partes em conflitos e que existem outras. E é nesse contexto que se responde ao primeiro questionamento levantado: a função de um processo judicial em um conflito familiar é garantir que os membros da família terão seus direitos resguardados.

Cabe então fazer o segundo questionamento: um processo é o meio adequado para solucionar conflitos familiares? Infelizmente essa questão não pode ser respondida por uma simples dicotomia do sim ou não. Ela requer uma análise mais detalhada. Responder com um sim a este questionamento traria essa ideia de que a função de um processo é solucionar conflitos, e, como já explicado, anteriormente, esta não é a função daquele.

Ademais, responder com um sim, seria esquecer toda a questão da autonomia privada que já fora aqui tão explorada. As pessoas possuem liberdade de escolher se querem ou não fazer uso do processo, porque existem outras formas de resolução de conflitos, como 
logo será explicado. Por outro lado, responder a tal questionamento com um não, seria esquecer que existem casos em que se faz necessário o uso do processo, porque são conflitos em que, necessariamente, alguém precisa da proteção estatal, como nos casos que envolvem menores ou incapazes.

Talvez a impossibilidade de responder de forma mais objetiva a esse questionamento permeie ao formato em que a pergunta foi realizada. Nesse ponto, o terceiro questionamento inicial do trabalho se faz necessário para esclarecer mais o assunto: até que ponto as famílias deverão solucionar seus conflitos precisando de um processo?

As famílias são livres para escolher se querem fazer o uso da "tecnologia do processo" ou não, excetuando-se os casos em que o conflito envolve menor ou incapaz, onde necessariamente o Estado precisa garantir seus direitos fundamentais. Nos demais casos os membros familiares possuem autonomia para tal decisão. Se quiserem optar em utilizar o processo para se cercarem das garantias que ele oportuniza, ótimo. Mas se não quiserem, pois preferem resolver através de um diálogo, melhor ainda.

A autonomia privada deve sempre prevalecer. Cada indivíduo que compõe a família tem o direito de escolher. É necessário quebrar o paradigma de que conflitos familiares só se resolvem por processos judiciais e que é mister a figura do juiz para que se chegue a uma conclusão. O juiz não existe para tentar achar a melhor solução para o caso, ele existe para garantir direitos fundamentais.

Muitas vezes a decisão dele faz aumentar o conflito original, gerando mais ainda a discórdia na família, fazendo com que as pessoas se sintam ultrajadas pelo poder judiciário. Mas essa decisão do juiz não é um erro do processo, porque o processo não serve para solucionar conflitos como já explicado anteriormente. É necessária essa percepção da realidade. Portanto, se a família quiser priorizar sua autonomia em detrimento das garantias fundamentais que o processo oferece, ela pode.

E então surge o quarto e último questionamento desta pesquisa: como priorizar essa autonomia? Quais as outras alternativas? Existe mais de uma resposta e, inclusive, alguns responderiam a opção "da violência”, mas, obviamente, não é a intenção desse trabalho defendê-la, até porque não existe autonomia plena em uma situação de uso de força para se impor à vontade de alguém. O objetivo aqui é priorizar um mecanismo simples, pacífico e que promova o diálogo entre as partes, privilegiando a soberania destas, para que juntas cheguem a um consenso: a mediação. 
A mediação não é um mecanismo novo, porém, nessa atual busca por meios que privilegiem a autonomia das partes, ela ganhou forças, tendo sido inclusive regulamentada pela Lei $\mathrm{n}^{\circ}$ 13.140/15. Além de privilegiar a autonomia e a liberdade, a função dela é estimular e desenvolver soluções para problemas que sejam aceitas por ambas as partes através do consenso, como mostra a própria lei da mediação:

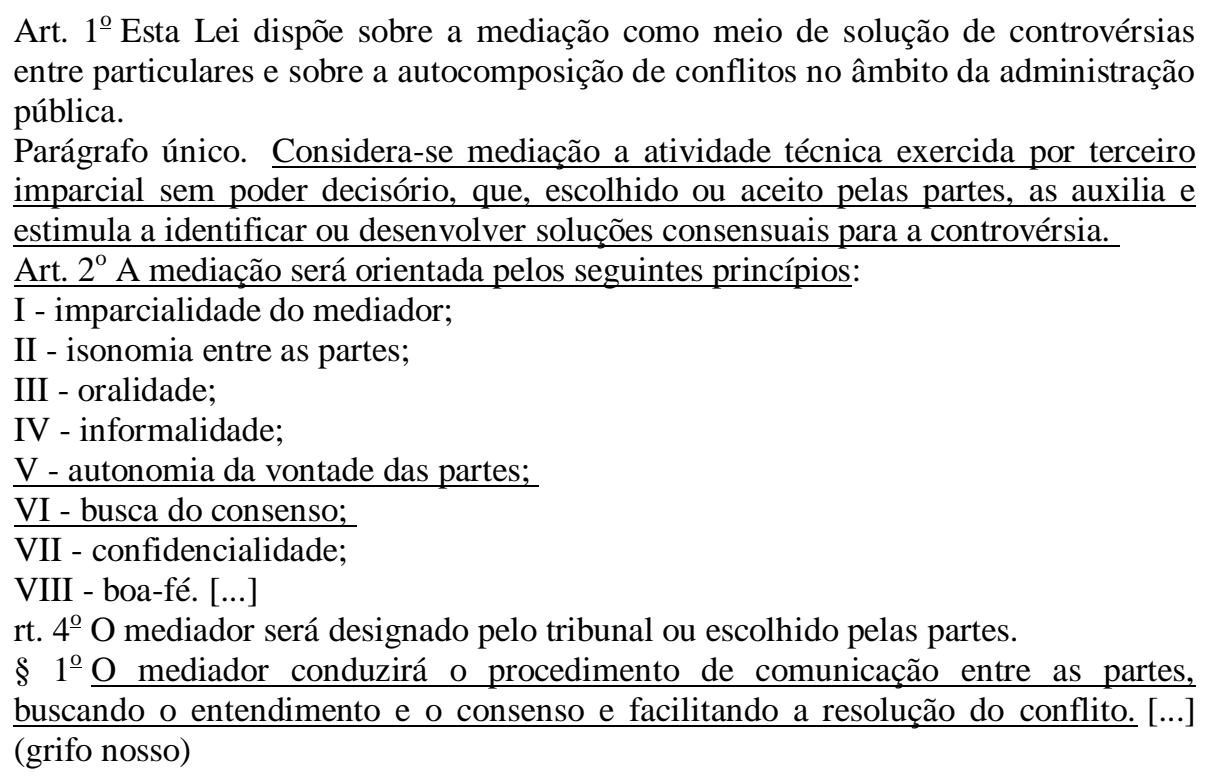

Visto a importância e utilidade do mecanismo da mediação e respondidos os questionamentos iniciais da pesquisa, percebe-se que a mediação, como meio alternativo de gestão de conflitos, serve para concretizar a tão necessária autonomia privada dentro do Direito de Família, enaltecendo a capacidade decisória e de diálogo dos membros familiares.

\section{CONCLUSÃO}

Como visto, em termos gerais, o presente trabalho visa analisar: se há autonomia privada na família; a função de um processo judicial; se este objetiva ou não solucionar um problema no âmbito do direito de família e, por fim, analisar qual o outro meio alternativo de gestão de conflitos familiares que pode concretizar a tão sonhada autonomia privada no âmbito familiar.

No primeiro tópico, se observou que a cada dia surgem novas formas de arranjos familiares. Houve uma mudança no conceito, nas características e na função da família na sociedade atual, agora regidas pelo afeto. Tal situação ocasionou a necessidade de diminuição 
da intervenção estatal no âmbito da vida particular de seus cidadãos e no reconhecimento de uma maior autonomia privada aos seus membros.

No segundo tópico, foi feito um histórico do surgimento do Direito Processual como ciência separada do Direito Material, de Oscar Bülow até as concepções de processo que se têm nos dias de hoje. Foram vistas as influências de Franz Klein e seu código processual austríaco; de Giuseppe Chiovenda e Francesco Carnelutti no processualismo italiano; de Enrico Tullio Liebman, que trouxe tal teoria para o Brasil; de Alfredo Buzaid, que as aplicou no Código de Processo Civil Brasileiro de 1973 e de Cândido Rangel Dinamarco, que a aperfeiçoou e difundiu pela doutrina, originando a escola Instrumentalista.

Por outro lado, foi analisada também a história da outra linha de pensamento processualista: desde James Goldschmidt e sua teoria da situação jurídica; passando por Fazzalari e a consolidação da diferença entre processo e procedimento; seguidos por Andolina e Vignera e o modelo constitucional do processo; finalizando em José Alfredo de Oliveira Baracho que trouxe, aperfeiçoou e difundiu a visão democrática do processo no Brasil. Por entender que esta é a visão mais compatível de processo com um Estado Democrático, como o brasileiro, optou-se por utilizá-la no presente trabalho.

No terceiro e último tópico do artigo, respondeu-se aos questionamentos iniciais feitos na introdução e no tópico 1, que visavam analisar até que ponto era necessário um processo judicial em uma questão que envolveria direito de família e qual a possível alternativa ao processo. Percebeu-se com o auxílio das análises feitas no tópico 2 que o processo judicial não objetiva solucionar conflitos, e, sim, garantir direitos fundamentais das partes.

Dessa forma, conclui-se que, com exceção dos casos que envolvem menores ou incapazes, nos quais se faz necessária a presença do Estado para resguardar seus interesses, nos demais casos, optar pelo processo judicial é uma das alternativas que a família possui, pois esta tem autonomia suficiente para escolher que caminho tomar, sendo, nesse contexto, a mediação uma excelente opção para fortalecer e concretizar a autonomia privada no âmbito do Direito de Família.

\section{REFERÊNCIAS}


ANDOLINA, Ítalo; VIGNERA, Giuseppe. I fondamenti costituzionali della giustizia civile: Il modello costituzionale del proceso civile italiano. 2. ed. Torino: G. Giappichelli Editore, 1997.

BARROS, Flaviane de Magalhães. O processo, a jurisdição e a ação sob ótica de Elio Fazzalari. Virtuajus. Revista Eletrônica da Faculdade Mineira de Direito, Belo Horizonte, v. ano 2, p. 01-29, 2003.

BATTOCHIO, Mariana. A Constituição Federal, princípios e valores informadores do estado democrático de direito e dignidade da pessoa humana como parâmetro de interpretação jurídica. In: Âmbito Jurídico, Rio Grande, XVII, n. 120, jan 2014. Disponível em: $<$ http://www.ambitojuridico.com.br/site/?n_link=revista_artigos_leitura\&artigo_id=14221>. Acesso em 17 maio 2017.

BERGER, Peter L.. Perspectivas sociológicas: Uma visão humanística. 12. ed. Petrópolis: Editora Vozes, 1986.

BRASIL. Constituição (1988). Constituição da República Federativa do Brasil. Brasília, Disponível em: <https://www.planalto.gov.br/ccivil_03/constituicao/constituicaocompilado.htm>. Acesso em: 17 maio 2016.

BRASIL. Lei $\mathrm{n}^{\mathrm{o}}$ 13.140, de 26 de junho de 2015. Mediação. Disponível em: <http://www.planalto.gov.br/ccivil_03/_ato2015-2018/2015/Lei/L13140.htm>. Acesso em: 20 maio 2017.

BÜLOW, Oskar von. La teoria de las excepciones procesales y los presupuestos procesales. Buenos Aires: Ediciones Jurídicas Europa - América, 1964. Traducción de Miguel angel Rosas Lichtschein.

CASTILLO, Niceto Alcalá-Zamora y. História, pensamento e terminologia processuais. Revista de Derecho Procesal. Argentina, 1947.

COUTO, Lindajara Ostjen. O direito fundamental da autonomia privada no Direito de Família. In: Âmbito Jurídico, Rio Grande, XII, n. 64, maio 2009. Disponível em: $<$ http://www.ambitojuridico.com.br/site/index.php?n_link=revista_artigos_leitura\&artigo_id=6119>. Acesso em: 17 maio 2017. 
FAZZALARI, Elio. Instituições de Direito Processual. Campinas: Bookseller, 2006.

GONÇALVES, Aroldo Plínio. Técnica processual e teoria do processo. Belo Horizonte: Del Rey, 2012.

LARAIA, Roque de Barros. Cultura: um conceito antropológico. Rio de Janeiro: Zahar, 1986.

LOBO, Paulo. Direito civil - Famílias. São Paulo: Saraiva, 4ª Ed. 2011.

REIS, Luara Cristina Santos. A teoria constitucionalista do processo. Revista Jus Navigandi, ISSN 1518-4862, Teresina, ano 20, n. 4403, 22jul. 2015. Disponível em: <https://jus.com.br/artigos/40779>. Acesso em: 17 maio 2017

SOUZA, Carolina M. B. de. Família na contemporaneidade: mudanças e permanências. Caderno Crh, [s.1.], v. 21, n. 54, p.623-625, dez. 2008. FapUNIFESP (SciELO). http://dx.doi.org/10.1590/s0103-49792008000300014. Disponível em: <http://www.scielo.br/scielo.php?script=sci_arttext\&pid=S0103-49792008000300014>.

Acesso em: 19 maio 2017.

TEPEDINO, Gustavo. A Disciplina Civil-Constitucional das Relações Familiares. 2006.Disponível em: <http://www.egov.ufsc.br/portal/sites/default/files/anexos/15079-15080-1-PB.pdf $>$. Acesso em: 19 maio 2017 